SISTEMA
ELETRÔNICO
DE REVISTAS
SER I UfPR

\title{
Ainda podemos escapar do Homo destructor? Um apelo à lucidez e à coragem
}

\section{Can we still escape from Homo destructor? An appeal to lucidity and courage}

Gancille, J. M. Ne plus se mentir. Petit exercice de lucidité par temps d'effondrement écologique. Paris: Rue de l'échiquier, 2019.

Paulo Freire VIEIRA ${ }^{1,2^{*}}$, Marina Favrim GASPARINI ${ }^{2}$

${ }^{1}$ Departamento de Sociologia e Ciência Política, Universidade Federal de Santa Catarina (UFSC), Florianópolis, Santa Catarina, Brasil.

${ }^{2}$ Núcleo Transdisciplinar de Meio Ambiente e Desenvolvimento (NMD), Universidade Federal de Santa Catarina (UFSC), Florianópolis, Santa Catarina, Brasil.

${ }^{*}$ E-mail de contato: vieira.p@ufsc.br

Resenha recebida em 13 de novembro de 2019, versão final aceita em 25 de fevereiro de 2020, publicada em 19 de abril de 2020.

As evidências mais recentes de alterações drásticas nos macroprocessos de autorregulação do Sistema-Terra estão na ordem do dia. Elas projetam num novo patamar de complexidade a tomada de consciência da virulência associada à crise socioecológica global (Meadows et al., 2012; Steffen et al., 2018). Ao focalizar com novas lentes as tensões e os impasses que acompanham a evolução desta crise de escopo civilizatório, o livro de Jean-Marc Gancille, vem se tornando um registro ao mesmo tempo inquietante e inspirador. Ele interpela profundamente todos aqueles que, como cidadãos conscientes e preocupados com o destino do Homo sapiens sapiens, tentam se envolver na desmistificação de pseudo-soluções para uma crise que, em sua essência, compromete a manutenção das pré-condições de habitabilidade do planeta (Cabanes, 2016).

Na contramão dos argumentos mistificadores difundidos em uníssono por líderes políticos, econo- 
mistas neoliberais, juristas e diplomatas onusianos, intérpretes de grandes corporações transnacionais e mesmo pelos arautos da tecnociência sem consciência (Morin, 1996), Gancille nos propõe o cultivo de duas virtudes cardinais que poderiam substituir a esperança ingênua em abordagens reformistas e reativas para uma síndrome de alta complexidade e até o momento incoercível: lucidez e coragem (para virar o jogo e mudar radicalmente de orientação). Segundo ele, isto exigirá não só a capacidade de exercitarmos uma interpretação cada vez melhor informada dos novos indícios de danos irreversíveis no complexo metabolismo do Sistema-Terra. Ao mesmo tempo, somos convidados a decodificar a lógica profunda dos discursos oficiais que endossam e legitimam a reprodução dos crimes em série que vêm sendo cometidos contra a biosfera.

Suas ideias convergem com o "pessimismo metódico" de Bertrand Méheust (2009), que, por sua vez, nos previne contra o poder de sedução dos oxímoros potencializados pela propaganda política e comercial nas mídias globalizadas. Neste sentido, por meio deste neologismo estaríamos sendo contaminados por esta arte sutil de "aproximar, associar, hibridizar e/ou fundir duas realidades contraditórias, o que explica a diversidade de formas e de funções que ela pode assumir" (Méheust, 2009, p. 117). Como entender de outra maneira a disseminação em grande escala e o fortalecimento da crença no poder supostamente iluminador das referências a um "desenvolvimento neoliberal sustentável", a um "crescimento verde" ou a um esforço de "moralização dos mercados concorrenciais", dentre tantas outras típicas do catecismo neoliberal?

Para ambos os autores, somente uma metamorfose ao mesmo tempo cognitiva e ético-política nos capacitaria finalmente a pararmos de mentir para nós mesmos, abandonando crenças superficiais, dogmatizadas e, num certo sentido, reconfortantes. Dessa guinada transgressiva em nossas arriscadas navegações a bordo do Titanic dependeria a identificação de espaços de manobra ainda pouco visíveis na busca de intervenções regeneradoras de novo tipo. A proposta que compartilham é a de encorajar reações proporcionais à extrema gravidade da conjuntura atual, radiografando com acuidade redobrada o cenário das mega-catástrofes anunciadas que já estão a caminho.

Gancille inicia o livro buscando compreender melhor o fracasso sistemático da maior parte do receituário terapêutico anticrise que vem sendo proposto e aplicado nas últimas décadas. Mobiliza neste sentido os conceitos de dissonância cognitiva, elaborado pelo psicólogo social Léon Festinger, e de cisão de realidade, atribuído ao filósofo alemão Oskar Negt. A seu ver, se o primeiro nos ajuda a compreender melhor o sentido paradoxal da premissa de que "quanto mais sabemos, menos acreditamos naquilo que sabemos" (Dupuy, 2002), o segundo nos remete à reprodução do fenômeno das assimetrias vigentes nas relações entre os pactos internacionais firmados ao longo do tempo e as ações unilaterais adotadas com base nos princípios da soberania nacional (Aykut \& Dahan, 2015). Paralelamente, o autor atribui à mobilização exaustiva da retórica do "ainda há tempo" um papel determinante na ritualização enganosa dos (perturbadores) sinais de alerta emitidos pela comunidade científica internacional - e que geralmente acabam sendo filtrados e diluídos pelas mídias compromissadas com o status quo. Apatia e conformismo de segmentos majoritários da população mundial poderiam ser vistos como subprodutos exemplares da disseminação inflacionada desses subterfúgios conciliadores. 
Para embasar este ponto de vista, o autor apresenta evidências que sugerem a inexistência de qualquer sinal tangível, ou mesmo de quaisquer condições favoráveis, que indiquem uma disposição consequente e coordenada das elites de romper com a lógica profunda que vem alimentando a reprodução do cenário de business as usual. Ao contrário, o livro mostra de que maneira grande parte das ações em curso - a exemplo do chamado "consumo responsável" (difundido como um importante vetor de transformação social rumo à "sustentabilidade") ou do culto concedido às ações a jusante, pontuais e fragmentadas - têm servido, sobretudo, para fortalecer e legitimar as tendências estruturantes que estão nos conduzindo em ritmo acelerado a uma encruzilhada civilizatória.

Para Gancille, os mitos do crescimento material ilimitado e da ideologia do progresso, alinhados ao predomínio de uma ética antropocêntrica-utilitária, continuam impulsionando a dinâmica destrutiva da civilização termoindustrial. Ao evidenciar a incompatibilidade congênita da economia de mercado globalizada com a realidade implacável das leis naturais, ele problematiza não só os fundamentos epistemológicos e ético-políticos do "otimismo tecnológico" subjacente ao ideário produtivista. Indo além, caracteriza o debate atual sobre "tecnologias verdes" como um caso particularmente representativo dos efeitos contraprodutivos de um tipo peculiar de "pensamento mágico" que, paradoxalmente, tende a desfocar as ações voltadas a um tratamento de choque dos condicionantes mais profundos da crise socioecológica global.

Dessa forma, permanecem reprimidas intervenções antecipativo-preventivas a montante, coordenadas e em grande escala, inspiradas numa ecologia politica radical e voltadas ao exigente reaprendizado da arte de viver em paz em ecossistemas e biomas cada vez mais radicalmente perturbados. Mais precisamente, na longa lista de fatores que caracterizam essa extraordinária força de inércia da máquina industrialista-consumista transnacionalizada, Gancille destaca ainda: (i) os poderosos efeitos da colonização dos espíritos imposta pela "ideologia econômica" (Rist, 2007); (ii) os obstáculos à implementação de medidas impopulares ou políticas tabus num quadro de redistribuição justa do imenso fardo de conversão de setores inteiros da economia; (iii) a necessidade de conversão em tempo recorde da totalidade de um sistema sedimentado secularmente sob o princípio de crescimento econômico ilimitado (incluindo a revisão de serviços públicos e proteções sociais que fundamentam a coesão social); (iv) a prevalência de uma organização espacial moldada pela lógica produtivista; (v) o peso descomunal dos interesses imediatos das elites econômicas e das tecnocracias nacionais que detêm a prerrogativa da arbitragem orçamentária e que defendem ferozmente o status quo; (vi) os dilemas que acompanham geralmente a formação não só de democracias fortes, sob a garantia de Estados imparciais, mas também de uma governança globalizada, benevolente e bem coordenada; e (vii) o próprio risco existencial decorrente de um desengajamento efetivo do sistema em nome de uma cosmovisão ecocêntrica (Eckersley, 1992).

Outro tópico crucial que emerge da reflexão de Gancille diz respeito à necessidade de uma avaliação mais rigorosa do poder real de influência da contestação ecologista nas arenas de tomada de decisão política. Ele reconhece que, nos últimos tempos, o potencial transformador do ecologismo lato sensu não para de enfraquecer, subjugado pela extraordinária capacidade de cooptação exercida pe- 
la "mão invisível" dos mercados globalizados. Seu diagnóstico não poupa até mesmo algumas vertentes da nova corrente ideológica que começou a operar recentemente na França em nome da colapsologia (Servigne \& Stevens, 2015).

Respostas capazes de relevar seriamente esses impasses vêm se tornando, assim, cada vez mais escassas, e o vácuo ideológico decorrente estaria fortalecendo, agora "em tempos de colapso ecológico", a crença nas supostas virtudes das políticas econômicas e sociais instituídas nos cinco continentes. Rompendo decididamente com a ilusão de que ainda haveria tempo para reverter este quadro, na parte conclusiva do livro o autor apela ao "dever de lucidez", no sentido de "aceitar a dimensão trágica da situação, aguçar um espírito crítico sobre as raízes do desastre, não descartar a nossa responsabilidade, identificar e nomear o adversário, travar combate" (Gancille, 2019, p. 67). Na forja de antídotos mais potentes, ele insiste que "seria ilusório continuarmos acreditando que as mudanças políticas de corte estrutural consideradas indispensáveis ao surgimento de um outro mundo possivel poderiam realmente se concretizar à margem de embates radicalizados com o sistema dominante" (Gancille, 2019, p.73). O ponto é sem dúvida polêmico, e Gancille justifica sua posição ao constatar que as decisões políticas cruciais em relação ao processo de agravamento tendencial da crise planetária continuam a ser comandadas - impunemente - por lobbies cada vez mais poderosos envolvendo governos e grandes corporações transnacionais. Ao mesmo tempo, na linha dos intérpretes do Novo Direito Sistêmico, conviria ressaltar que, em grande parte, as arbitragens efetuadas atualmente em nome da Justiça Ambiental ainda permanecem tributárias não só de uma cosmovisão antropocêntrica-utilitarista (na contramão do processo de maturação do pensamento sistêmico-complexo contemporâneo), mas também das pesadas injunções estruturais impostas pela ortodoxia neoliberal (Cabanes, 2016; Capra \& Mattei, 2018).

Por outro lado, no bojo de um possível novo ciclo de contestações mais radicais, Gancille resgata o potencial embutido em experimentações com novos estilos de vida, inspirados no cultivo da austeridade voluntária, da autonomia local, da autenticidade e do senso de interconexão com a ecosfera. Ele acredita que essas inovações estariam acessíveis a todos e que, de certa forma, independeriam da conjunção de inúmeras variáveis externas articuladas ao pacto social hegemônico na globalização neoliberal. No rol destas últimas estariam incluídas, por exemplo, decisões governamentais, inovações técnicas, incentivos fiscais e normas derivadas dos arranjos institucionais em vigor.

Como salientamos acima, seria no prolongamento das evidências de ineficácia dos padrões usuais de respostas ao colapso planetário atual que conviria situarmos e avaliarmos criticamente a fecundidade da linha de reflexão proposta neste livro. Subvertendo a maior parte das crenças e ilusões que nos parecem ainda hoje evidentes - e que continuam influenciando decisivamente nossas ações individuais e coletivas de oposição a um modelo civilizatório ecocida -, as ideias de Gancille deverão certamente ocupar, nos próximos tempos, uma posição privilegiada na condução do debate ecológico-político contemporâneo. 


\section{Referências}

Aykut, S. C.; Dahan, A. Gouverner le climat? 20 ans de négociations internationales. Paris: Les Presses de Sciences Politiques, 2015.

Cabanes, V. Un nouveau droit pour la Terre. Pour en finir avec l'écocide. Paris: Éditions du Seuil, 2016.

Capra, F.; Mattei, U. A revolução ecojurídica: o Direito Sistêmico em sintonia com a natureza e a comunidade. São Paulo: Cultrix, 2018.

Dupuy, J. P. Pour un catastrophisme éclairé. Quand l'impossible est certain. Paris: Éditions du Seuil, 2002.

Eckersley, R. Environmentalism and political theory. Toward an ecocentric approach. London: UCL Press, 1992.

Meadows, D.; Meadows, D.; Randers, J. Les limites à la croissance dans un monde fini. Paris: Éditions Rue de l'échiquier, 2012.
Méheust, B. La politique de l'oxymore. Comment ceux qui nous governent nous masquent la réalité du monde. Paris: La Découverte, 2009.

Morin, E. Ciência com consciência. Rio de Janeiro: Bertrand Russell, 1996.

Rist, G. Le développement. Histoire d'une croyance occidentale. Paris: Presses de la Fondation Nationale des Sciences Politiques, 2007.

Steffen, W. et al. Trajectories of the Earth System in the Anthropocene. PNAS, 115 (33), p. 8252-8259, 2018. doi: $10.1073 /$ pnas. 1810141115

Servigne, P.; Stevens, R. Comment tout peut s'effondrer. Petit manuel de collapsologie à l'usage des générations présentes. Paris: Seuil, 2015. 